\section{General psychiatry in no-man's land}

MARTIN DEAHL and TREVOR TURNER

We decided to become psychiatrists because we liked talking to people, diagnosing and treating mental illness without gadgets or tests, and employing clinical skills acquired through experience and specific training. Today we barely have time to clarify the treatment and record the 'care plan'; our appointment schedules can resemble those of the average general practitioner (GP). This lack of face-to-face contact time has been highlighted by the Report of the Confidential Inquiry into Homicides and Suicides by Mentally Ill People as a common denominator of the lack of care for seriously ill patients (Steering Committee, 1996). Despite this constrained availability, we are still expected to accept limitless responsibility for 'supervision' of the mentally ill in the community and the hospital, via the GP or via an outdated 1983 Mental Health Act (MHA).

Given these multifarious roles it is not surprising that morale in adult general psychiatry is plummeting. Nowhere is this more so than in deprived inner-city areas where working conditions have become topsy-turvy, leading to newspaper headlines such as "Psychiatrists quit over risks to patients" (The Independent, 16 January 1996 , p. 11), or London's mental health service being called a "shambles" (Evening Standard, 16 January 1996, p. 3). Once prized senior lecturer posts, at leading London teaching hospitals, are now hard to fill. The similar difficulties of general practice in inner London reflect a parallel situation (Harris et al, 1996). Nationwide there are consultant shortages and numerous cancelled appointments committees.

\section{STATE OF THE WARDS}

Most acute adult psychiatric wards in our region (North Thames) have bed occupancy rates in excess of $120 \%$ (MILMIS Project Group 1995; Powell et al, 1995). The majority of these patients are compulsorily detained $(60-80 \%$ on our unit). There is no question of managing these cases in any other setting - all admissions are emergencies. Inner-city trusts also have substantial numbers of patients occupying beds in the independent sector, beds often miles from the local community and significantly more expensive than the NHS. Even so, about one-quarter of the patients in acute beds are there because no-one else can cope with their chronic, socially handicapping, psychological impairments (e.g. Lelliot et al, 1996). They are homeless, insightless and unloved, and alternatives are just not available (Fulop et al, 1996).

Many patients, with a significant forensic history or displaying 'challenging' behaviours, have been admitted from aftercare hostels, of varying denominations, and their return thereto is refused. They remain on acute wards as their last refuge: the high risk of relapse, the terms of the MHA, and the understandable inability of non-professional staff to treat them add to their demoralisation and that of their carers. Ever in the background on this psychiatric battlefield, is the rumble of gunfire from 'untoward incidents', rising complaints and formal inquiries. The constant reliance on agency staff (often $50 \%$ or more) reflects the sevenmonth burn-out time for a staff nurse on such units (details available from author).

\section{STATE OF THE DOCTORS}

Against this background how can one properly manage patients when so many factors are beyond one's control? Stigma, poverty, housing departments, and the diversities of short-staffed social service inputs are all shifting variables. Many Trusts face serious difficulties in both the recruitment and retention of medical staff. Young doctors are readily alarmed when they see the working conditions of their seniors (Today, 1995; Storer, 1996). This particularly applies to general adult psychiatry by contrast to sub-specialities such as forensic or old age psychiatry, in which practitioners are able at least to decide whom they are going to treat and when, with time for proper assessments and care plans.

Adult general psychiatry wards have no boundaries. They are the refuge of last resort for psychiatry's flotsam and jetsam. That is the strength and vocation of the generalist, but not if liability becomes unlimited. Consultants increasingly elect to retire at the earliest opportunity, or move into administrative positions as a means of escaping from the trench warfare engulfing the very patients they would like to talk to. In a recent national survey $88 \%$ of consultants admitted to wanting to leave the profession (Hospital Doctor, 1995). Even the traditional strategy of enhancing unpopular posts by adding senior lecturer sessions, offers cold comfort in a climate in which academics themselves are under pressure to increase their research productivity. But paperwork, tribunals and endless meetings merely erode research time, doubling the pressure.

\section{HOW DID WE GET HERE?}

History shows that psychiatry has usually been under-resourced, but various issues in the past five years have converged to bring about the current crisis. First and foremost, British medicine is in a state of demoralisation after the NHS reforms. These have increased administrative costs and the influence of managers, diminishing the perceived role of doctors. Psychiatry's additional problems arise as a result of society's continued misunderstanding of the nature of mental illness. This is reflected by the use of pejorative headlines such as "Crazed son walks free to butcher his mother" (Daily Express, 16 January, 1996, p. 20), or "From Bedlam to Bedsit" (The Economist, 2 September, 1995, p. 21). Such misconceptions are magnified by the fashion for alternative therapists, peddling anti-scientific nostrums fuelled by the nihilism of under-employment and excessive (mis)information. This distrust of medical approaches to mental illness is perfectly summarised in the headline "We're mad to trust shrinks" (Daily Mirror, 9 February, 1996, p. 7).

Furthermore, successive governments have followed a community care policy that is inherently flawed. While the majority of the long-term mentally ill can be primarily managed in the community (Anderson et al, 1993), there remains a continuing need for acute hospital beds. The one is not a 
substitute for the other. Premature discharges generate the unreal bed occupancy figures quoted above. The government shibboleth of the Care Programme Approach (CPA) (Department of Health, 1990; Kingdon, 1994) has failed to reduce readmission or suicide rates. We do not advocate a return to the asylums, but in closing the asylums, and with the best of intentions, we have only partially replaced their functions (Jones, 1996). These included acute care, rehabilitation, long-term sanctuary, security for dangerous offenders, a coherent management structure, and a social network that still remains elusive for many of the 'new long-stay'. The rising demand for medium-secure facilities reflects a key current shortage, yet the (cheaper) means of preventing forensic status is only now being acknowledged in the recent NHS executive review (e.g. The Independent, 1996).

\section{STATE OF THE LAW}

Recent changes in policy and legislation have only worsened matters. Following the Reed report (Reed, 1992), mentally abnormal offenders have been transferred into the NHS, through a combination of court diversion schemes (James \& Hamilton, 1991), and the increasing use of section 47 and 48 of the MHA by the prison medical service, under pressure from a Home Office embarrassed by suicides in custody (Home Office Research and Statistics Department, 1995). There have been no additional resources to cope with this substantial influx, and there is no financial responsibility on either the Home Office or the courts for insisting on prolonged admissions. Within forensic circles the term "low security' confuses the role of a locked, intensive-care ward, with continuing custody for patients awaiting legal disposal. Once in the community, where assertive community teams by definition limit their case-load to, say, 15 patients per worker, what happens when number 16 turns up? There is no funding transfer, yet the consultant is designated the Responsible Medical Officer (RMO).

Furthermore, recent guidance from the Department of Health demanding complex pre-discharge arrangements is compounding the trend towards 'defensive' medicine. Following the high media profile of community tragedies such as the care of Christopher Clunis (Ritchie, 1994) and the death of Jonathan Newby (Davies, 1995), all provider Trusts are now required to conduct inquiries into all "untoward incidents" (Department of Health, 1994). These inquiries serve a positive function in improving standards, in generating pressure for further resources, and in reassuring bereaved families and the public. However, they are time-consuming and expensive, they usually reiterate the recommendations of previous inquiries (i.e. to improve communication, written procedures, etc.) (Sheppard, 1995), and are notably stressful for all involved. It is also known that predicting suicide and untoward incidents is, to say the least, problematic (Gunnell \& Frankel, 1994). For example, a recent Home Office review of relapsed patients under MHA section 41 supervision showed ". . . that it was seldom possible, even with hindsight, to identify cases where preventative action could have been taken" (Home Office Research and Statistics Department, 1995).

The latest panic measures are the Supervision Register (Department of Health, 1994) and the Supervised Discharge Order, a legislative amendment that became active in April 1996 (Department of Health, 1993). These are bureaucratic conceptions concocted far from the front-line realities of clinical care (cf. Caldicott, 1994; Bottomley, 1994). They bring no extra staff nor additional powers to treat patients in the community; they are complex in terms of procedure and paperwork; they explicitly increase the personal responsibility of the RMO. It is our view that these proscriptions are anti-therapeutic (Eastman, 1995), a view supported by MIND and other interested parties. Their sole aim is to devolve responsibility from the central government, enabling ministerial blandishments about no patient leaving hospital without a full 'care plan' in place, while forgetting the acute psychotics crowding casualty, waiting for a bed.

\section{STATE OF RESEARCH}

Much modern research (Falloon et al, 1982; Hoult \& Reynolds, 1984; Dean \& Gadd, 1990; Merson et al, 1992; Muijen et al, 1992; Burns et al, 1993) has suggested that acutelyill patients can be managed successfully at home, avoiding hospital admission. This has been misconstrued by the Department of Health and by health authorities to mean that numbers of hospital beds can be reduced. Resistance to this notion is seen as retrogressive, as indicative of consultants equating beds with power. Yet much community research has been based on short-term, well- funded projects, using enthusiastic research teams who soon move on (Coid, 1994). Such research takes little account of the chronic consequences, including staff burn-out, the burden on families forced to care for disturbed relatives, and the community rejection generated by repeated breakdown. There are benefits of care in the community (via GP outreach clinics, home-based assessments, and normalisation of lifestyles), yet the workaday difficulties of travelling, communicating, training juniors and time management, remain to be addressed. It is noteworthy how few researchers go on working within their 'model' services, and difficult not to take the view that financial rather than therapeutic considerations prevail.

\section{WHAT IS TO BE DONE?}

Long-term solutions to the crisis must go beyond mere funding. A variety of measures could be introduced, requiring little additional expenditure, that would significantly improve the present situation. Joint purchasing of services for the mentally ill (by health and local authorities) can more effectively integrate resources (Hadley \& Goldman, 1995). The Home Office and the Courts should have financial accountability for the patients they impose on the NHS. Likewise, patients no longer requiring an acute admission bed and who meet agreed criteria for a hostel place should be funded by local authority social services departments.

The continuing closure of the asylums should be halted (98 out of 121 open 10 years ago will have closed by the year 2000 ; Phillips, 1995) and the need for long-stay hospital beds reviewed. New legislation is required to enable psychiatrists, when necessary, compulsorily to treat mentally ill patients in the community. Such a community treatment order would, it has been suggested, contravene European human rights legislation, yet the existing MHA section 41 restriction order already operates as such. Legislation is required that is preventive and therapeutic rather than reactive and court-engendered.

Unless serious efforts are made to address these issues, we predict a further decline in morale among staff and an exodus from the profession. If clinical psychiatry continues to be seen as an unrewarding, frustrating and even a dangerous activity, particularly in the inner city where many of the academic teaching centres are located and most research conducted, then the 
future of the profession and the academic base of clinical neuroscience may be damaged beyond repair. Urban deprivation has traditionally been the breeding ground for the idealism of student-driven academe all over the world. First-class practitioners are central to this elison of social need and professional vocation.

Our predecessors were forced into superintending enormous, stigmatised, crowded "bins". We, by contrast should be educating and researching, in schools, homes and workplaces, face-to-face with patients, carers and co-workers, linking hospital and community. We should adopt a more robust stance in arguing for needs-led resources and legislative changes that will protect patients, their families and service provision. Now that all general psychiatrists are, by and large, community-based, the responsibility of the generalist needs to be defined. Specialists can only exist, by definition, when there is a healthy general service acting as gatekeeper (Mathers \& Hodgkin, 1989). No consultant psychiatrist should be required to act both as doctor and keyworker, nor to assume responsibility for excessive case-loads. If generalism is not protected, we will end up back behind the asylum walls, sheltered but ineffectual, turnkeys for government bureaucrats.

\section{ACKNOWLEDGEMENTS}

We thank our local colleagues for their helpful comments in the preparation of this paper, and their support for the ideas we express.

\section{REFERENCES}

Anderson, J., Dayson, D., Wills, W., et ol (1993) The TAPS project. 13: Clinical and social outcomes of long-stay psychiatric patients after one year in the community. British journal of Psychiatry. 162 (suppl. 19), 45-56.

Bottomby, V. (1994) Reply to the College's response to supervision registers. Psychiotric Bulletin, 18. 387-388.

Burns, T., Beadsmoore, A., Bhat, A. V., et ol (1993) A controlled trial of acute home-based psychiatric services. I: Clinical and social outcome. British journal of Psychiatry. 163. 49.54 .

Caldicott, F. (1994) Supervision registers: the College's Response. Psychiatric Bulletin, 18. $385-386$.

MARTIN DEAHL, FRCPsych, TREVOR TURNER, FRCPsych, St Bartholomew's, Hospital, London

Correspondence: Dr Martin Deahl, Department of Psychological Medicine. St Bartholomew's Hospital, West Smithfield, London ECIA 7BE

(First received 4 March 1996, revised 10 September 1996, accepted 23 October 1996)

Coid, J.W. (1994) Failure in community care: psychiatry's dilemma. British Medical Journal, 308. 805-806.

Davies, N. (1995) Report of the Inquiry into the Circumstonces Leading to the Death of jonathan Newby. London: HMSO.

Dean, C. \&add, E. M. (1990) Home treatment for acute psychiatric illness. British Medical Journal, 301. 1021-1023.

Department of Health (1990) The Core Progromme Approoch for People with a Mental IIness Referred to the Specialist Psychiatric Services. Joint Health/Social Services Circular HC (90)23/LASSL(90) II. London: Department of Health.

- (1993) Legal Powers on the Care of Mentally III People in the Community. Report of the Internal Review. London: Department of Health.

- (1994) Introduction of Supervision Registers for Mentally III People from I April 1994. HSG(94)5 London: Department of Health

Eastman, N. (1995) Anti-therapeutic community mental health law. British Medical Journal, 310, 1081-1082.

Fulop, N. J., Koffman, J., Carson, S., et al (1996) Use of acute psychiatric beds: a point prevelence survey in North and South Thames regions. Journal of Public Health Medicine, 18. 207-216.

Falloon, I. R. H., Boyd, J. L., McGill, C. W., et al (1982) Family management in the prevention of exacerbation of schizophrenia. New England Journal of Medicine. 306. 1437-1440.

Gunnell, D. Frankel, F. (1994) Prevention of suicide: aspiration and evidence. British Medical Journol, 308. 1227-1233.

Hadley, T. R. Q Goldman, H. (1995) Effect of recent mental health and social service policy reforms on Britain's mental health system. British Medical Journal, 311. 1556- 1558.

Harris, T., Silver, T., Rink, E., ot ol (1996) Vocational training for general practitioners in inner London. Is there a dearth? And if so what's to be done. British Medical Journal. 312. 97-101.

Home Office Research and Statistics Department (1995) The Supervision of Restricted Potients in the Community. Research Findings no. 19. London: Home Office.

Hosprtal Doctor (1995) Why consultants want out. September 14, p.7.

Hoult, J. E. \& Reynolds, I. (1984) Community orientated treatment compared to psychiatric hospital orientated treatment. Social Science and Medicine. 18, 1005-1010.

James, D. \& Hamilton, L. (1991) The Clerkenwell scheme: assessing efficacy and cost of a psychiatric liaison service to a magistrates court. British Medical Journal, 303. 282-285.
Jones, K. (1996) Psychiatrists and the community. A case of cognitive dissonance? British journal of Psychiatry, 168. 677-668.

Kingdon, D. (1994) Care programme approach: recent government policy and legislation. Psychiotric Bulletin, 18. 68-70.

Lelliott, P., Knapp, M., Audini, B., et ol (1996) Mental health residential care in the 1990s: beds and balances. Mentol Health Research Review, 3. 24-27.

Mathers, N. \& Hodzkin, P. (1989) The gatekeeper and the wizard: a fairy tale. British Medical Journal, 298. 172-173.

Merson, S., Tyrer, P., Onyett, S., at al (1992) Early intervention in acute psychiatric emergencies: a controlled clinical trial. Loncet, 339, 1311-1314.

MILMIS Project Group (1995) Monitoring inner London mental illness services. Psychiatric Bulletin, 19, 276-280.

Muijen, M., Marks, I., Connolly, J., et al (1992) Home-based care and standard hospital care for patients with severe mental illness: a randomised clinical trial. British Medical journal, 304. 749-754

Phillips, E. (ed.) (1995) Mind over Matter. A Study of the Country's Threatened Mental Asylums. Save Britain's Heritage.

Powell, R. B., Hollander, D. \& Tobiansky, R. I. (1995) Crisis in admission beds. A four-year survey of the bed state of greater London's acute psychiatric units. British fournal of Psychiatry. 167. 765-769.

Reed, J. (1992) Review of Health and Social Services for Mentally Disordered Offenders and Others Requiring Similar Services. London: HMSO.

Ritchie, J. H. (1994) The Report of the Inquiry into the Care and Treatment of Christopher Clunis. London: HMSO.

Sheppard, D. (1995) Learning the Lessons. Mental Health Inquiry Reports Published in England and Wales between 1969-1994 and their Recommendations for Improving Practice. London: Zito Trust.

Steering Committee of the Confidential Inquiry into Homicides and Suicides by Mentally III People (1996) Report of the Confidential Inquiry into Homicides and Suicides by Mentally III People. London: Royal College of Psychiatrists.

Storer, D. (1996) Recruitment into psychiatry. Psychiatric Bulletin, 20. 177.

The Independent (1996) The politicians take over the asylum. 21 February. pp. I. 13.

Today (1995) Young docs fleeing NHS. 15 August, p. 2. 